\title{
REDESIGNING A JADE DESIGN COURSE THROUGH INTEGRATION OF THREE-DIMENSIONAL TECHNOLOGY
}

\author{
Wang MANQIAN ${ }^{1}, \mathrm{Kim}_{\text {EUNYOUNG }}{ }^{1}$ and Yang MAN ${ }^{2}$ \\ 'Japan Advanced Institute of Science and Technology, Japan \\ ${ }^{2}$ Lecturer of Fashion and Accessory Department of Dalian Polytechnic University, Japan
}

\begin{abstract}
This study aims to explore the process by which the traditional jade design curriculum can adapt to the changing technological and industrial trends, through educational experimental settings. The research mainly uses curricular integration and cooperation with enterprises to improve the teaching mode of traditional jade design courses. The research develops a set of instructional methods for the jade design course, by combining 3D digital technology with the heritage of jade culture. To reduce the gap between academia and industry, the design of the experiment is based on the occupational standards and social demands that jade designers must fulfil. The results show that 3D technology can help students to perform better in complex and accurate three-dimensional design, to meet the needs of enterprises. In addition, 3D design can help schools to decrease teaching costs and reduce environmental pollution, which can protect both jade resources and students' health. Moreover, the jade design course can maintain its own cultural heritage in teaching and retain high-quality traditional culture, as guidance for designing the teaching content in combination with 3D technology.
\end{abstract}

Keywords: Jade design course, 3D digital modelling, traditional craft education, curriculum integration, employment demand

\section{INTRODUCTION}

New technologies and traditional crafts need not be mutually exclusive [1], as digital technology can play a role in safeguarding heritage crafts [2]. For instance, Kim states that 3D technology can invest new meaning in traditional handicrafts [3]. However, according to Eckerson, the application of 3D technology in the design courses of colleges and universities is only the initial stage [4]. Jade design education in China has long been conducted through traditional teaching methods, given the cultural context of craftsmanship [5]. In this study, we reviewed the current curriculum of jade design in Chinese higher educational institutes (HEIs), and conducted an educational experiment using 3D digital technology in a jade design course in 2019, in order to develop a set of instructional methods that combine 3D digital technology with traditional design-teaching methods.

\section{REVIEW OF JADE DESIGN CURRICULUM IN CHINESE HEIS AND RELATED INDUSTRY}

Jade carving has a long history in China, dating back to 5000 BC [6]. However, the advance of 3D technology has influenced the jade design industry, as the designers are required to master this technology. In this regard, educational reform of the jade design courses has been undertaken in HEIs. We reviewed the current curriculum of jade design in Chinese HEIs, to determine the target of the educational experiments in this study and identify the gaps between academia and industry.

\subsection{Jade design curriculum in Chinese HEls}

As shown in Figure 1, the objectives of jade design courses can be divided into three categories: the first is courses established for geological (jewellery) academy undergraduates in the fields of earth science and materials science. This class of students is mainly engaged in the identification, grading, and jewellery design [7] of jade. The second type is vocational and technical education based on jade 
processing; the objective is to train skilled labourers and various practical talents in the professional skills needed in society. The third category includes jewellery design majors, apparel product design majors, sculpture majors, etc., in art design colleges.

The main target of this study is the third category, concerning the teaching-course planning of jade design courses offered in art and design colleges. The experimental object is a jade design course under the direction of the fashion and apparel design department of the School of Fashion. The following content also explores the teaching of precious jade courses in such schools.

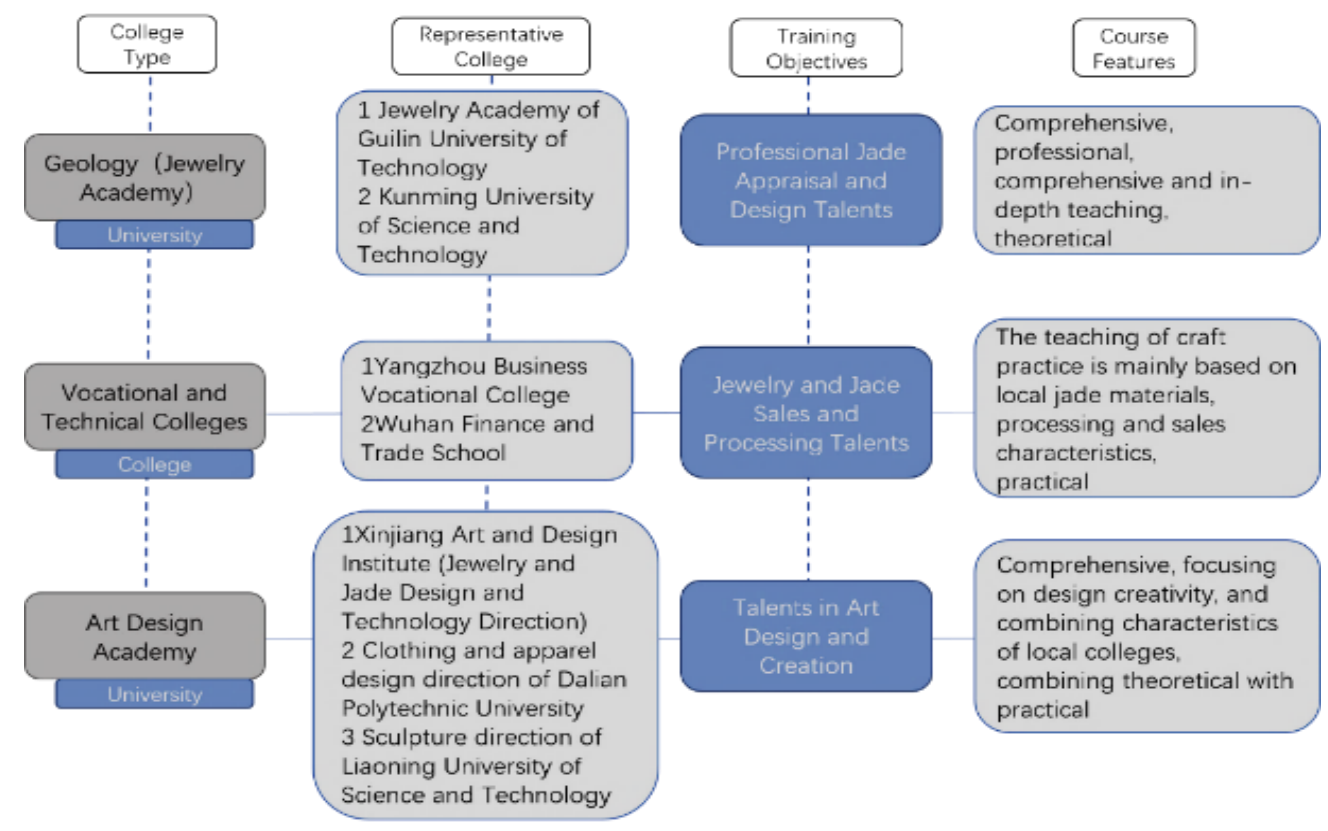

Figure 1. Comparison of jade design courses in different institutes

\subsection{Investigation of the design status of jade design enterprises}

With the purpose of investigating the training of jade design talents, we inspected two jade-related companies: the Ximu Jade Company in Xiuyan County; and Kunlun Jade Jewellery Co., Ltd., located in Shui Bei. Kunlun Jade Company is the biggest and most famous jewellery and jade design and processing centre in China; it emphasizes modern and fashionable design that employs the combination of jade and precious metal materials. This requires designers to flexibly use design software; they also need excellent abilities in hand-painting jewellery and in design innovation. However, there is no requirement for their proficiency in jade processing and carving. Ximu Jade Company emphasizes the designer's knowledge structure and cultural background, that can design based on classical style.

\section{EXPERIMENTAL DESIGN}

According to the review of jade design curricula in Chinese HEIs and related industry, the main aim of the courses is to integrate traditional jade with new design ideas and technology; this enables the students to understand the artistic beauty of jade and to become proficient in designing software to fulfil the industry's demand for design talents. This experiment was carried out with a course on clothing and apparel design in Dalian Polytechnic University, from May to June 2019. The total class time was 48 academic hours, with a total of 18 students, and two teachers participated in the course teaching. The specific experimental content and processes were as follows.

\subsection{Adjusting the teaching process through curriculum integration}

Curriculum integration has been recognized as an effective and reasonable method of integrating teaching resources, to help students solve practical problems [8]. In this regard, the main aim of the curriculum was to arouse students' interest and solve practical problems according to the culture of jade design. As shown in Figure 2, the jade design course in 2018 consisted of five parts; the course focused on ancient jade modelling and culture, and students' 3D modelling skills were not reflected in the jade course. In 2019, we adhered to the basic theory of jade materials and the teaching content of ancient jade modelling and culture. In addition, students used 3D printing to print out wax models for metal and 
3D engraving models, made sufficient preparations for the production of Rhino design software, and the creative design part was combined with the jade course in the second part. In this way, a reasonable integration was made, on the basis that the teaching time of the two courses and the teaching staff were unchanged. Students could exercise and further enhance their ability to use 3D software in the jade course, and the software made the course more efficient. Also, the combination of courses now differed from the single form of traditional craft courses. The two teachers gave advice and guidance from different perspectives, to encourage students' learning.

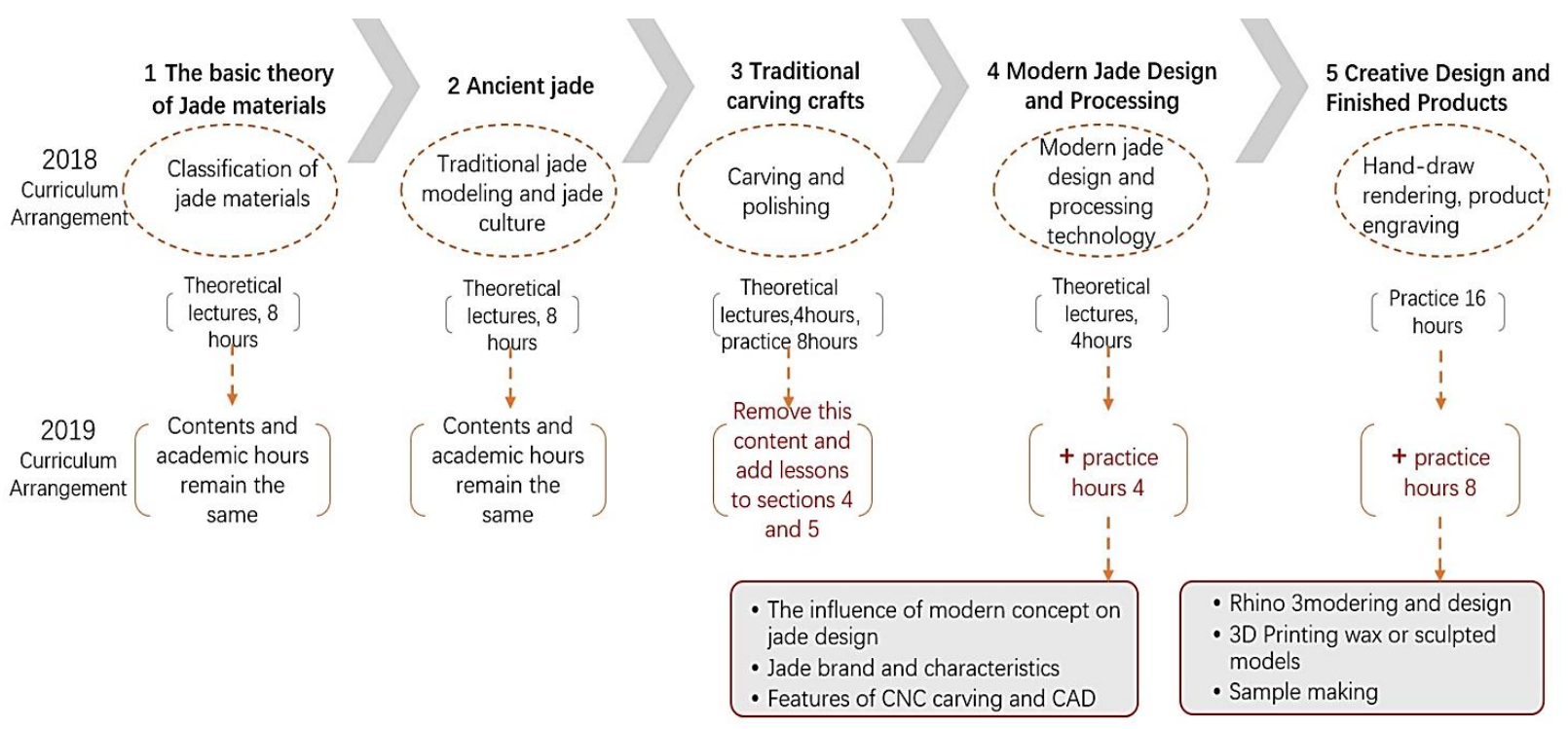

Figure 2. Adjustment of course in 2019

\subsection{Cooperation with enterprises to set course theme and evaluation criteria}

The theme was set in cooperation with Kunlun Jade Jewellery Co., Ltd. Based on cutting-edge market information and jade design trends, the company suggested the theme of adhering to the heritage of traditional culture. It was required that the material be composed of jade with other jewellery materials and preferably with precious metal, for a stylish design [9]. For the precious metal part, students could employ 3D in the hard gold, ancient gold, and enamelling processes that are popular in the jewellery industry and market. The evaluation criteria of the course were mainly decided by the two teachers and a designer from Kunlun Jade enterprise. The theme and novelty of the design assignment and the finished effect accounted for the most points, at 20\% respectively. The tradition of jade culture and fashionable design were also important valuation indicators.

\section{RESULTS}

The sample data of 18 participants' homework outputs in 2018 and 2019 were respectively evaluated based on eight criteria, with four scales (see Table 1). We tested the significant differences between the two different educational settings for each evaluation criterion, and found that our new teaching methods had a positive effect on "effective expression $(\chi 2=7.48, \mathrm{p}<0.05)$ " and on "rendering effect $(\chi 2=7.11$, $\mathrm{p}<0.05)$ ", but a negative effect on "cultural heritage $(\chi 2=9.02, \mathrm{p}<0.05)$ " (

Table 1. Comparison of students' finished homework results in 2018 and 2019 ( $N=36)$

\begin{tabular}{|c|c|c|c|c|c|c|c|c|c|}
\hline \multirow{2}{*}{ Grading contents } & \multicolumn{9}{|c|}{ Ranking } \\
\cline { 2 - 12 } & \multicolumn{2}{|c|}{ Excellent } & \multicolumn{2}{|c|}{ Good } & \multicolumn{2}{|c|}{ Fair } & \multicolumn{2}{c|}{ Pass } \\
\cline { 2 - 11 } & 2018 & 2019 & 2018 & 2019 & 2018 & 2019 & 2018 & 2019 \\
\hline Themes and creativity (20\%) & 4 & 6 & 8 & 9 & 4 & 3 & 2 & 0 \\
\hline Fashion and market transformation (10\%) & 3 & 5 & 5 & 8 & 6 & 3 & 4 & 2 \\
\hline Effective expression (10\%) & 2 & 6 & 5 & 9 & 8 & 3 & 3 & 0 \\
\hline
\end{tabular}




\begin{tabular}{|c|c|c|c|c|c|c|c|c|}
\hline Series design (10\%) & 5 & 5 & 4 & 6 & 3 & 5 & 6 & 2 \\
\hline Cultural heritage (10\%) & 6 & 3 & 8 & 2 & 2 & 8 & 2 & 5 \\
\hline Craftsmanship and details (10\%) & 3 & 5 & 3 & 6 & 6 & 4 & 6 & 3 \\
\hline Reasonable use of materials (10\%) & 2 & 3 & 3 & 3 & 7 & 8 & 6 & 4 \\
\hline $\begin{array}{c}\text { Finished effect, Similarity with the rendering } \\
\text { effect (20\%) }\end{array}$ & 2 & 5 & 3 & 8 & 5 & 3 & 8 & 2 \\
\hline
\end{tabular}

Table 2. Chi-square Test calculation for the comparison of students' homework

\begin{tabular}{|c|c|c|c|c|c|c|}
\hline \multirow{3}{*}{ Grading contents } & \multicolumn{4}{|c|}{ Actual Value } & \multirow{3}{*}{ Expected Value } & \multirow{3}{*}{ P Value } \\
\hline & \multicolumn{2}{|c|}{ Sum of High } & \multicolumn{2}{|c|}{ Sum of Low } & & \\
\hline & 2018 & 2019 & 2018 & 2019 & & \\
\hline Themes and creativity & 12 & 15 & 6 & 3 & $13.5,4.5,13.5,4.5$ & 0.248 \\
\hline Fashion and market transformation & 8 & 13 & 10 & 5 & $10.5,7.5,10.5,7.5$ & 0.090 \\
\hline Effective expression & 7 & 15 & 11 & 3 & $11,7,11,7$ & $0.006 * *$ \\
\hline Series design & 9 & 11 & 9 & 7 & $10,8,10,8$ & 0.502 \\
\hline Cultural heritage & 14 & 5 & 4 & 13 & $9.5,8.5,9.5,8.5$ & $0.003 * *$ \\
\hline Craftsmanship and details & 6 & 11 & 12 & 7 & $8.5,9.5,8.5,9.5$ & 0.095 \\
\hline Reasonable use of materials & 5 & 6 & 13 & 12 & $5.5,12.5,5.5,12.5$ & 0.717 \\
\hline $\begin{array}{l}\text { Finished effect, Similarity with the } \\
\text { rendering effect }\end{array}$ & 5 & 13 & 13 & 5 & $9,9,9,9$ & $0.008 * *$ \\
\hline
\end{tabular}

\subsection{Enhancing students' motivation to design more complex structures}

In 2018, due to the lack of three-dimensional shaping ability, students' ideas were limited to planar graphics, and the representation of the pattern in two-dimensional space. As can be seen in Figure 3, though both series of designs are creative, there are no design changes on the sides and back. This is because students had not received training in three-dimensional design in long-term pre-courses, and often thought from a single perspective. Students' assignments in 2019 clearly show that 3D software had enabled multi-angle design and thinking. Figure 4 depicts that the students used three-dimensional design to exceed the traditional design approach. The data in Table 1 show that the students achieved higher scores in creativity, and in fashion and market transformation. After 3D software use, jade and other gemstones' design goes beyond the traditional shapes and patterns, breaks the constraints of traditional design themes and frames, adds a sense of fashion and modernity, and differs from the traditional jade-carving teaching; this reflects its advantages for art majors in universities.

\subsection{D data provides higher accuracy}

By comparing the finished results of students' homework in 2018 and 2019, we found that the final effect was improved with 3D software. Due to a lack of engraving experience, students' work demonstrated a poor combination of the metal and jade parts in the final product (Figure 3). In 2019, with the high accuracy of 3D technology, and using 3D printing of wax moulds to cast silver, the jade part could be designed accurately with Rhino. This also overcame the design limitations that made students afraid of choosing complicated shapes, because of the difficulties in the production process when combining jade and metal to enhance the quality of design. Moreover, students generated a series of designs quickly and with higher accuracy, which reduced the duplication of tasks. Commercial jade designs emphasize the series design effect. In traditional jade design and production, students must undertake the repeated drawing of a single element and of modelling in production, which allows limited time for design improvement. But with Rhino modelling software, students can store their design files 


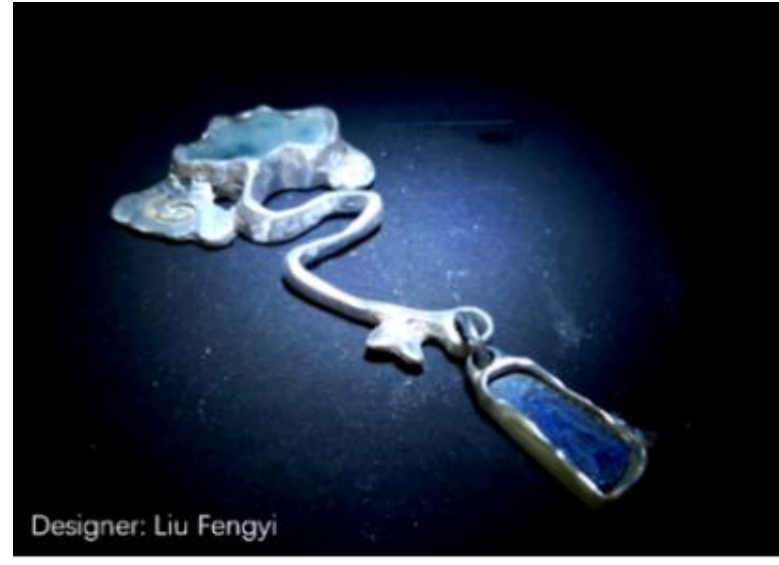

Figure 3. The final work by hand engraving

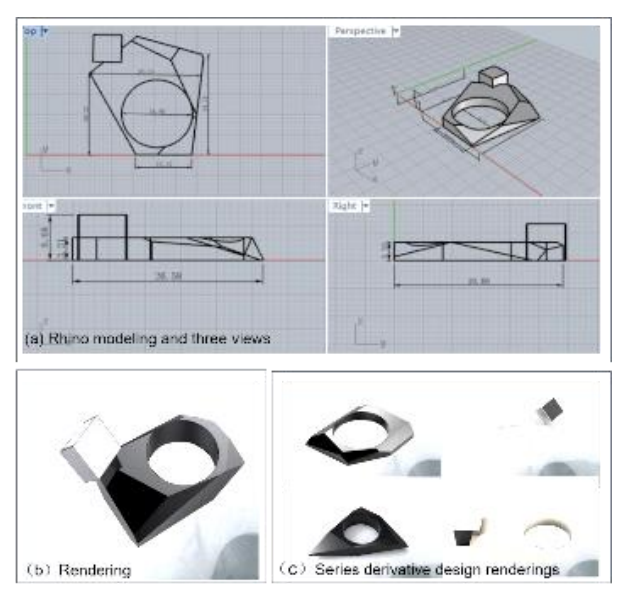

Figure 4. Series design using Rhino

in a database, to reduce repetitive work; furthermore, the original element can be reproduced quickly to generate a series of design works (Figure 4).

\subsection{Stimulating students' creativity through photo-level displays}

Traditional jade design courses adhere to hand-drawing in the design renderings. Students found it difficult to express the dimensional details, which led them to simplify processes when designing, and thus affected their creative design. Figure 5 shows the Rhino modelling effects in work by the same student. The photo-level effects of this tool allow students to see every detail in a 360-degree rotation; this inspires students to enrich three-dimensional modelling and craft details, when guided by seeing the expected performance in different directions [10]. Adopting Rhino has standardized the design works of students and enables them to adapt to the rules of corporate design in their future careers.
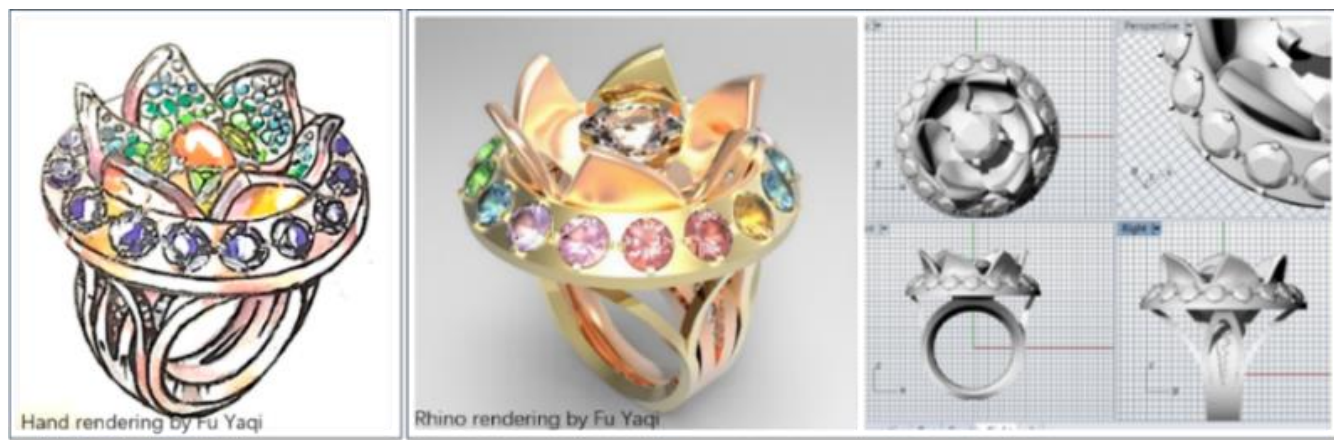

Figure 5. Comparation of hand-rendering and Rhino modelling effects by the same student

\subsection{Reducing the cost of teaching and improving health conditions}

Although practical training is an important part of the jade design course, the high cost of jade materials has greatly increased the learning costs of schools and students. Furthermore, the jade materials are nonrenewable resources and cannot be carved repeatedly. This is a major disadvantage for teaching, as student learning is a process of trial and error and improvement. Through 3D modelling and simulation, students could avoid repeated errors in the learning process. In addition, the impact of jade dust on students' health is an important issue to be considered in the course, as it damages the lungs [11]. The jade-carving tasks were reduced through 3D modelling, thus enabling students to express design ideas conveniently and quickly, while ensuring their safety.

\section{CONCLUSIONS}

Our educational experiment enhanced students' motivation to design structures of greater complexity, and with higher accuracy. Moreover, adopting the 3D technology in the jade design course can provide students with photo-level displays, which can stimulate their creativity and meet the needs of the current jade industry. Also, use of 3D technology can help universities and students to reduce the cost of teaching, and to improve the health conditions with eco-friendly tools. 
The implementation method of combining related courses enables students to consolidate their software skills, and experience 3D modelling techniques in practical project operations. Linking related courses in the design curriculum can move beyond the traditional form of education in craft courses and can inspire and drive students to be more creative.

However, there are limitations of our study. The design theme was not specific enough for students to generate their unique ideas in a short time. In addition, due to the incorporation of a metal part, students' focus shifted to the design of this element rather than the jade. For our future study, we suggest giving students a more specific design theme, and the proportion of jade in the final design and the finished product should be specifically determined.

\section{REFERENCES}

[1] Turlif V. et al. U. Digital preservation of traditional crafts and three-dimensional modelling technologies, International Journal of Arts and Sciences, 2010, 3(9), pp.1-10.

[2] Elizabeth A. and Marcelle S. Intangible heritage management: An investigation of the role of digital technology in safeguarding heritage crafts in the UK now and in the future, Degree Paper of MA of Historic Royal Palaces and Queen Mary University of London, 2019.

[3] Jun-Tae K. ScholarWorks @UNIST, Combining 3D printing with traditional crafts: Why is it needed and what is the role of the designer? Available: https://scholarworks.unist.ac.kr/handle/201301/18343, (2016) February.

[4] Eckerson N. Integration of 3-Dimensional Modelling and Printing into Fashion Design Curriculum: Opportunities and Challenges, International Textile and Apparel Association Annual Conference Proceedings, 2018, pp.1-6.

[5] Su X. Beijing Jade carving, Southeast University Press Publishing, 2016, pp.168-169

[6] Margaret S. et al. The identification of carving techniques on Chinese jade. Journal of Archaeological Science. Vol. 31, No. 10, 2004, pp. 1413-1428,

[7] Tang X. et al. The "going out" strategy of jewellery department of Kunming university of science and technology, Science and Technology Innovation Herald, 2012, pp. 175-177

[8] Gert N. and John L. Curriculum integration: Twenty questions- with answers. Becoming: Journal of the Georgia Middle School Association. Vol. 30, Issue 1.

[9] Meng X. S. and Yang R. J. The innovation of plain gold jewellery and gold inlaid with jade, Chinese Gems and Jades, 2014 Available: http://www.cnki.com.cn/Article/CJFDTotalGBYS201402003.htm

[10] Liu Z. Q. Digital jade carving, China University of Geosciences Press Co. LTD., 2013, pp.9-11

[11] Anupama P. and Rachel G. Exploration of 3D printing to create zero-waste sustainable fashion notions and jewellery, Fashion and Textiles, 2018, https: //doi.org10.1186/s40691-018-0152-2

This research is the result of the Liaoning Science Planning Fund Project "Research on the Activation Form of Hongshan in Liaoning Jade Cultural and Creative Industries under the Background of Industrial Transformation and Cultural Revival" (2017J059) 